\title{
Clinical Characteristics and Outcome of Infantile Fibrosarcoma: A Retrospective Single-institution Review
}

\author{
Enas El Nadi ${ }^{1,2}$, Mona Moustafa ${ }^{2}$, Gehad Ahmed ${ }^{3,4}$, Alaa Younes ${ }^{4,5}$, Mohamed Saad Zaghloul ${ }^{6,7}$, \\ Naglaa El Kinaai $^{8,9}$, Amal Rafaat ${ }^{10,11}$, Elham Khaled ${ }^{12}$, Sayed Abdel Hamid ${ }^{2,13}$ \\ ${ }^{1}$ Department of Clinical Oncology, Faculty of Medicine, Beni - Suef University, Beni-Suef, Egypt \\ ${ }^{2}$ Department of Pediatric Oncology, Children Cancer Hospital of Egypt (CCHE) Cairo, Egypt \\ ${ }^{3}$ Department of Surgery, Faculty of Medicine, Helwan University, Helwan, Egypt \\ ${ }^{4}$ Department of Surgical Oncology, Children Cancer Hospital of Egypt (CCHE) Cairo, Egypt \\ ${ }^{5}$ Department of Surgical Oncology, National Cancer Institute, Cairo University, Cairo, Egypt \\ ${ }^{6}$ Department of Radiotherapy, National Cancer Institute, Cairo University, Cairo, Egypt \\ ${ }^{7}$ Department of Radiotherapy, Children Cancer Hospital of Egypt (CCHE) Cairo, Egypt \\ ${ }^{8}$ Department of Surgical Pathology, National Cancer Institute, Cairo University, Cairo, Egypt \\ ${ }^{9}$ Department of Surgical Pathology, Children Cancer Hospital of Egypt (CCHE) Cairo, Egypt \\ ${ }^{10}$ Department of Radiodiagnosis, National Cancer Institute, Cairo University, Cairo, Egypt \\ ${ }^{11}$ Department of Radiodiagnosis, Children Cancer Hospital of Egypt (CCHE), Cairo, Egypt \\ ${ }^{12}$ Department of Clinical Research Children Cancer Hospital of Egypt (CCHE), Cairo, Egypt \\ ${ }^{13}$ Department of Pediatric Hematology/Oncology, National Cancer Institute, Cairo University, Cairo, Egypt
}

Email address:

inas.mohsen@57357.com (E. El Nadi)

\section{To cite this article:}

Enas El Nadi, Mona Moustafa, Alaa Younes, Gehad Ahmed, Mohamed Saad Zaghloul, Naglaa El Kinaai, Amal Rafaat, Elham Khaled, Sayed Abdel Hamid. Clinical Characteristics and Outcome of Infantile Fibrosarcoma: A Retrospective Single-institution Review. Cancer Research Journal. Vol. 8, No. 2, 2020, pp. 26-35. doi: 10.11648/j.crj.20200802.12

Received: March 18, 2020; Accepted: April 9, 2020; Published: April 28, 2020

\begin{abstract}
Analysis was done to the clinical characteristics and outcome of children with infantile Fibrosarcoma (IFS) who were treated at Children's Cancer Hospital Egypt (CCHE). A Retrospective chart review of all pathologically confirmed IFS patients treated at CCHE from July 2011 till December 2016. Detailed demographic, pathological, and clinical data of 27 IFS patients were collected, analyzed and correlated with treatment outcome and survival. We enrolled 27 patients with a median age 0.23 years (range $0.03-3.8$ ), $54 \%$ were females. Extremities were the commonest primary site $(59.3 \%$ ), followed by head and neck (22.2\%). The tumor size was $>5 \mathrm{~cm}$ in 18 patients, $<5 \mathrm{~cm}$ in six and undetermined in three. It was resectable without preoperative chemotherapy in three patients. Twenty one received preoperative VAC (Vincristine, Actinomycin-D and Cyclophosphamide) of those nine cases received second line Ifosphamide and Adriamycin to improve respectability. Overall survival of the whole group of patients was $82.3 \%$. We need to increase sample size and to get facility for proper diagnosis by genetic analysis in such difficult cases for better pathological diagnosis
\end{abstract}

Keywords: Infantile Fibrosarcoma, Risk Factors, Survival

\section{Introduction}

Soft tissue sarcomas account for $7.4 \%$ of all malignancies younger than 20 years of age [1]. Infantile fibrosarcoma also called Congenital Fibrosarcoma, Desmoplastic Fibrosarcoma of Infancy or Fibrosarcoma of Soft Tissue - Infant [34]
This tumor arises from mesenchymal cells and composed of malignant fibroblasts within a collagen background.[8]

Congenital Infantile fibrosarcoma (CIFS) is the most common non-rhabdomyosarcoma soft tissue tumor with an incidence of $24.5 \%$ of all soft tissue sarcomas seen in the first year of life [2]. It can be present at birth or can develop during the first 5 years, 
particularly in infants and toddlers younger than 2 years; $80 \%$ of cases are diagnosed during the first year of life [3-5]. Approximately $40 \%$ of CIFs are diagnosed in infants younger than 3 months of age and most commonly presents as a nontender, poorly circumscribed mass varying in size and consistency $[6,7]$. CIFS in a newborn period is a rare morbidity [9]. Compared with the adult form of fibrosarcoma, IFS is characterized by a lower incidence of metastasis $(<10 \%)$, a higher probability of long-term survival ( $90 \%$ at 5 years), and greater chemosensitivity [7-10].

Most cases share the distinctive feature of the specific translocation $\mathrm{t}(12 ; 15)$ leading to the gene fusion ETV6NTRK3.

The extremities, particularly the distal segments, are most often involved; $70 \%$ of the reported cases occur at this site, followed by the head and neck and then the trunk [11, 12]. The tumor tends to grow rapidly, and the initial clinical diagnosis is often erroneous [12].

In contrast to adult fibrosarcomas, the infantile form is considered as a low-grade malignant tumor with an excellent prognosis (33). This disease rarely metastasizes (less than $10 \%$ ) and has a good prognosis with survival rate is approximately $80 \%-90 \%$ [34]

Standard treatment of IF has been primarily surgical, with wide local excision encompassing histologically free margins being the goal without additional radiation or chemotherapy $(11,12)$. Recent reports suggest that chemotherapy has a beneficial role in the management of initial unresectable IF and in reducing the need for extensive surgery or amputation [13-18].

Surgical excision has been the mainstay of treatment over the last few decades, but a few patients receive additional chemotherapy or radiotherapy [3, 7] Primary excision can entail a radical and even mutilating procedure that results in high morbidity. Recent studies have continued to advocate surgery and have added chemotherapy and radiotherapy in select conditions [3, 20]. Loh et al. [21] reviewed 11 patients with IFS and concluded that initial chemotherapy combined with surgery is a successful treatment. A recent multi- institutional European study concluded that conservative surgery is the mainstay of treatment, and alkylating agent and Anthracycline-free first-line chemotherapy should be used to treat unresectable tumors [2]).

\section{Patients and Methods}

A retrospective review to patients charts included all newly diagnosed patients with a diagnosis of infantile fibrosarcoma presented to the Children Cancer Hospital Egypt (CCHE 57357), from July 2007 to December 2016.

Investigations at Diagnosis

All studied patients had complete physical examination, initial routine lab and Assessment of the extent of the primary tumor was done by computed tomography (CT) scan and/or magnetic resonance imaging (MRI). Metastasis was excluded by CT scan of the chest, bone scan with or without PET scan. Pathologic review of representative tissue slides was done for all patients enrolled in the study.

Pathology of Infantile Fibrosarcoma

Gross Findings

The tumors vary in size from few centimeters to large mass. Some patients may present with huge mass with skin ulceration. Most tumors are poorly circumscribed, fusiform, or disk-shaped. Cut section is grey-white or pale pink with or without central necrosis. Other tumors may showed myxoid, cystic or hemorrhagic changes.

Microscopic Findings

Most tumors are composed of sheets of solidly packed, spindle-shaped cells that are uniform in appearance and arranged in bundles, imparting a herringbone appearance. The cells show little nuclear pleomorphism and frequent mitoses. Some tumors may have abundant collagen. Bizarre and multinucleated giant cells are rare. Scattered chronic inflammatory cells are common. Hemangiopericytoma-like pattern may be prominent.

Immunohistochemical Findings

Positive reaction: vimentin, smooth muscle actin (variable), h-caldesmon (variable).

\begin{tabular}{|c|c|c|c|}
\hline & Drug & Age & Dose \\
\hline \multirow{3}{*}{$\mathbf{v}$} & \multirow{3}{*}{ Vincristine } & 23 years & $1.5 \mathrm{mg} / \mathrm{m}^{2} \times 1$ (maximum dose $\left.2 \mathrm{mg}\right) \mathrm{N}$ push \\
\hline & & 21 year and $<3$ years & $0.05 \mathrm{mg} / \mathrm{kg} \times 1$ (maximum dose $2 \mathrm{mg}$ ) IV push \\
\hline & & $<1$ year & $0.025 \mathrm{mg} / \mathrm{kg} \times 1$ (maximum dose $2 \mathrm{mg}$ ) IV push \\
\hline \multirow{2}{*}{ A } & \multirow{2}{*}{ Dactinomycin } & 21 year & $0.045 \mathrm{mgkg}$ (maximum dose $2.5 \mathrm{mg}) \mathrm{NVX} 1$ \\
\hline & & $<1$ year & $0.025 \mathrm{mg} / \mathrm{kg} \mathrm{IV} \mathrm{x} 1$ \\
\hline \multirow{2}{*}{ c } & \multirow[b]{2}{*}{ Cyclophosphamide } & 23 years & $1200 \mathrm{mg}_{\mathrm{m}} \mathrm{m}^{2} \mathrm{IV} \mathrm{X} 1$ \\
\hline & & $<3$ years & $40 \mathrm{mg} / \mathrm{kg}$ IV X I \\
\hline \multicolumn{4}{|c|}{$\begin{array}{l}\text { MESNA and fluids will be used with Cyclophosphamide. } \\
\text { MESNA: The recommended total daily MESNA dose is equal to } 100 \% \text { of the daily cyclophosphamide dose and is administered at } 0,3,6 \text {, and } 9 \text { hours after cyclophosphamide start. } \\
\text { Fluids: Suggested hydration pror to cyclophosphamide dose is } 200 \mathrm{~mL} / \mathrm{m}^{7} / \text { hour. Urive specific graviry should be } \leq 1.010 \text { before cyclophosphamide is begun. Suggested hydration after } \\
\text { cyclophosphamide dose is } 3 \mathrm{~L} / \mathrm{m}^{2} \text { over } 24 \text { hours. }\end{array}$} \\
\hline \multicolumn{4}{|c|}{ If there is an age change during treatment, use the new appropnate age dosing in the next cycle. } \\
\hline \multicolumn{4}{|c|}{$\begin{array}{l}\text {-Chemotherspy cycles may begin when the ANC } \geq 750 / \mu \mathrm{L} \text { and platelets } \geq 75,000 / \mu \mathrm{L} \text { after nadir and hepatic function is as follows: } \\
\text { - Total bilinbin } \leq 1.5 \mathrm{x} \text { upper limit of normal for age AND - SGPT (ALT) } \leq 2.5 \times \text { upper limit of nommal for age } \\
\text { Dose modification for hematological toricity: } \\
\text { If ANC }<750 / \mu \mathrm{L} \text { and platelets }<75,000 \text {; pospone the dose for one week, if criteria are met, give full dose. } \\
\text { If ANC }<750 / \mu \mathrm{L} \text { and platelets }<75,000 \text {; for more than one week, wait till the criteria met and give the dose with } 25 \% \text { dose reduction except (Vincristine) and in the next } \\
\text { chemotherapy course reducton to } 25 \% \text { if criteria not met more than one week, if tolerated give fill dose in subsequent cycles. (for repeated delay consider GSCF) }\end{array}$} \\
\hline
\end{tabular}

Figure 1. VAC protocol of chemotherapy.

I -Ifosfamide $3 \mathrm{~g} / \mathrm{m}^{2} /$ dose IV on Days $1,2,3\left(9 \mathrm{~g} / \mathrm{m}^{2} /\right.$ cycle) with mesna.

D-Doxorubicin $37.5 \mathrm{mg} / \mathrm{m}^{2} /$ dose IV on Days $1,2\left(75 \mathrm{mg} / \mathrm{m}^{2} /\right.$ cycle, max total dose $150 \mathrm{mg} /$ cycle $)$

Mesna and IV fluids are taken according CCHE guidelines 
Negative reaction: myogenin, CD99, synaptophysin Cytogenetic and Molecular Genetic Findings

Most tumors have chromosomal translocation $t(12 ; 15)$ (p13; q25), which result in fusion of the ETV6 gene on chromosome 12 with the neurotrophin-3 receptor NTRK3 gene on chromosome 15 . This translocation can be detected by RT-PCR or FISH, yet both are not available. But we working to get it for future application to infantile fibrosarcoma cases

Management

All patients were assessed initially for the possibility of primary surgical excision, but those who were clearly unresectable on imaging at diagnosis, they started neoadjuvant chemotherapy. The standard chemotherapy regimen was VAC. On failure to achieve resectability by VAC they received Ifosfamide /Adriamycin as second line.

\section{Statistical Analysis}

Data obtained were summarized as Mean + SD (standard deviation) and per-centages. Event-free survival (EFS) was defined as the period from the date of diagnosis until evidence of an event (progressive disease, relapse, or death) or last contact, whichever occurred first. Overall OS time was defined as the period from the date of diagnosis until death or last contact, whichever occurred first.

Correlations between different demographic factors of infantile fibrosarcoma were done using Chi-square test or Fisher exact. P-values less than 0.05 were considered significant.

Treatment response

In patients with measurable disease, response to chemotherapy was assessed after two cycles of chemotherapy by assessment of radiologically-identified tumor volume reduction: i.e. complete response (CR) Z complete disappearance of visible tumor with no residual disease; major partial response (PR 2/3)

$\mathrm{Z}$ volume response $66 \mathrm{e} 99 \%$; minor $\mathrm{PR}(<2 / 3) \mathrm{Z}$ volume response $34 \mathrm{e} 65 \%$; stable disease (SD) $33 \%$ reduction in tumor volume; progressive disease (PD) $\mathrm{Z}$ more than $40 \%$ increase in the sum of the volumes of all measurable lesions, or the appearance of new lesions

\section{Results}

Newly diagnosed patients with a diagnosis of infantile fibrosarcoma who presented to the Children Cancer Hospital Egypt (CCHE 57357), from July 2007 to December 2016 were studied. Twenty seven children were included during the study period, with a median age 0.23 years (range $0.03^{-}$ 3.8 ), and $55.6 \%$ were females. Extremities were the commonest primary site $(59.3 \%)$. (Patients characteristics of the whole study cohort are summarized in table 1).

Table 1. Clinical characteristics.

\begin{tabular}{llll}
\hline category & frequency & Percentage & Valid percentage \\
\hline Female & 15 & 55.6 & 55.6 \\
male & 12 & 44.4 & 44.4 \\
\hline
\end{tabular}

\begin{tabular}{llll}
\hline category & frequency & Percentage & Valid percentage \\
\hline$<=1$ year & 18 & 66.7 & 33.3 \\
$>1$ year and & 9 & & \\
$<5$ years & 16 & 59.3 & 59.3 \\
Extremities & 6 & 22.2 & 22.2 \\
Head \& Neck & 3 & 11.1 & 11.1 \\
PELVIC & 2 & 7.4 & 7.4 \\
Trunk & & & \\
LNS: N0 & 16 & 59.3 & 59.3 \\
LNS: N1 & 9 & 33.3 & 33.3 \\
LNS: UK & 2 & 7.4 & 7.4 \\
$<5$ cms & 6 & 22.2 & 22.2 \\
$>5$ cms & 18 & 66.7 & 66.7 \\
Unknown & 3 & 11.1 & 11.1 \\
\hline
\end{tabular}

\section{Management}

Regarding the first line of treatment: 3 patients did not receive chemotherapy (the treatment was only surgery)

Twenty four cases had surgery 6 cases had initial surgery and 18 cases had delayed surgical excision after chemotherapy

Seventeen cases with positive margins after surgery 13 from them did not relapse, under follow up and in complete remission.

Twenty one cases received neoadjuvant chemotherapy, 3 cases had chemotherapy post relapse and 3 cases did not receive chemotherapy.

Fifteen patients received neoadjuvant chemotherapy in the form of VAC. They were assessed for surgery every 2 cycles (3 patients received 6 cycles of VAC then surgery, 4 patients received 4 cycles of VAC then surgery, 4 patients received 3 cycles of VAC then surgery, 3 patients received 2 cycles of VAC then surgery, 1 patient received 1 cycle of VAC then shifted to surgery because he developed toxicity from chemotherapy

4 patients received 4 cycles of VAC then shifted to I/D (1 patient from the 3 had no surgery), 3 patients received 2 cycles of VAC then shifted to I/D protocol, 1 patient received 1 cycle of VAC then 6 cycles of I/D Six cases received radiotherapy only one case received postoperative radiotherapy due to postoperative residual and 5 cases had postoperative radiotherapy after resurgery and adjuvant chemotherapy.

Table 2. Management of infantile fibrosarcoma patients.

\begin{tabular}{llll}
\hline category & frequency & Percentage & Valid percentage \\
\hline Local control & & & \\
Surgery & 18 & 70.4 & 70.4 \\
Surgery and rth & 6 & 22.2 & 22.2 \\
None & 2 & 7.4 & 7.4 \\
Type of surgery & & & \\
Delayed & 21 & 51.9 & 51.9 \\
Initial & 3 & 40.3 & 40.3 \\
Margins & & & \\
Negative & 7 & 29.6 & 29.6 \\
Positive & 17 & 63.0 & 63.0 \\
Chemotherapy & & & \\
Neoadjuvant & 21 & 77.7 & 77.7 \\
Chemotherapy & & 11.1 & 11.1 \\
Postoperative cth & 3 & 11.1 & 11.1 \\
None & 3 & & \\
\hline
\end{tabular}




\section{Outcome}

For all 27 patients, the 5-year event-free survival was $82.3 \%$, and the 3 -year overall survival was $70.4 \%$. Survival outcomes in relation to different patients' parameters were done. Correlation with survival to site of lesion, initial tumor size, method of local control No recurrence of IFS tumor was reported in twenty patients. 7 cases relapsed, all relapsed cases had resurgery followed by radiotherapy in 3 patients of them received chemotherapy IFOSF /ADR with resurgery and radiotherapy 4 cases had resurgery followed by radiotherapy

2 cases received Pazobanib after failing of IFOSF/ADR and radiotherapy on palliative intent and both showed progression

Four patients died, 3 patients from disease progression and one case from toxicity.

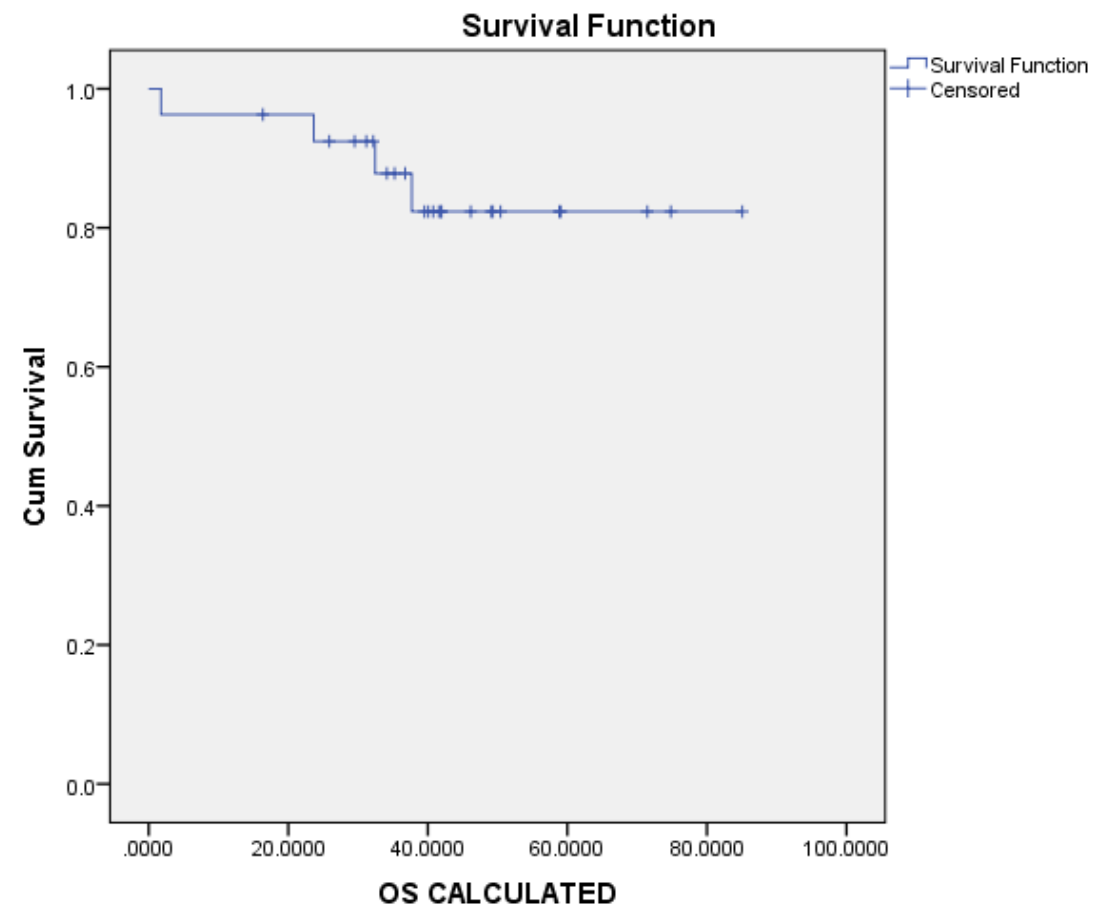

Figure 2. Overall survival (OS): $82.3 \%$.

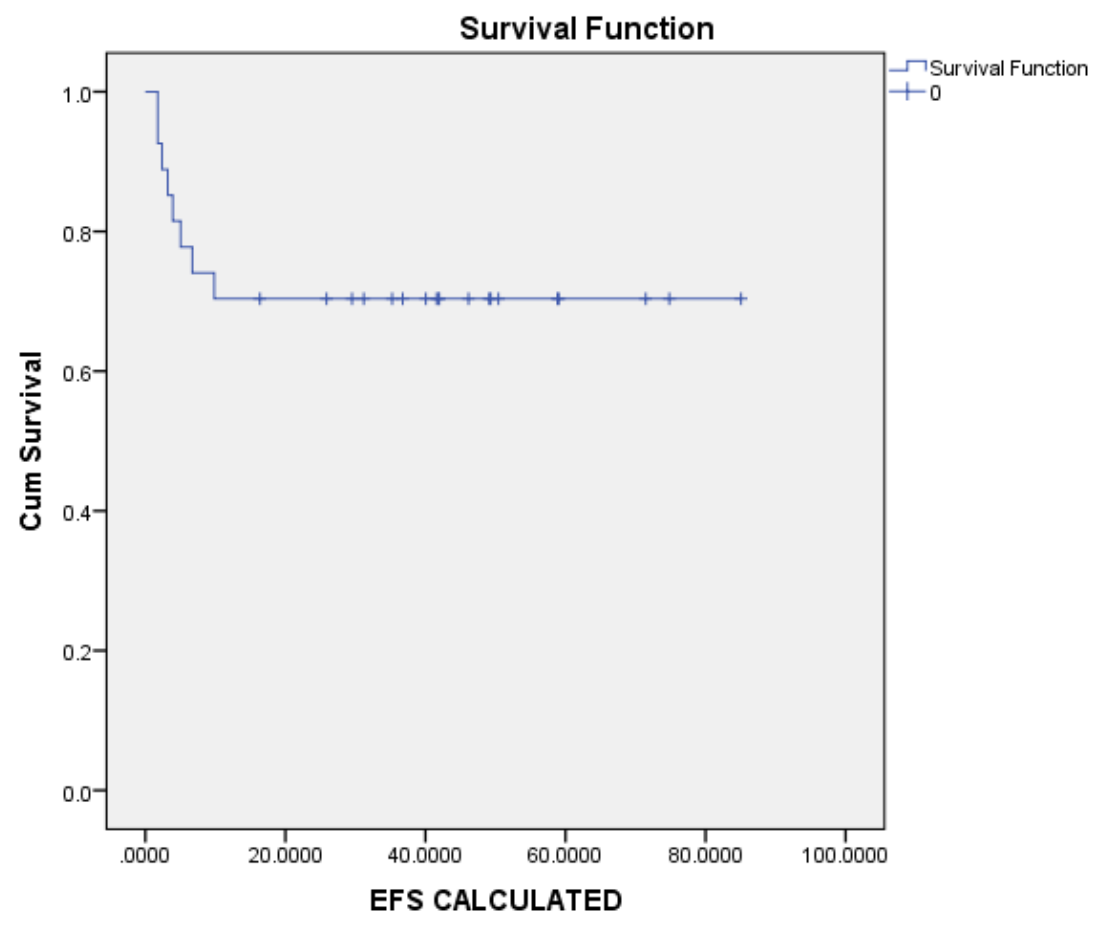

Figure 3. Event Free Survival (EFS) AT 5 YEARS: 70.4\%. 


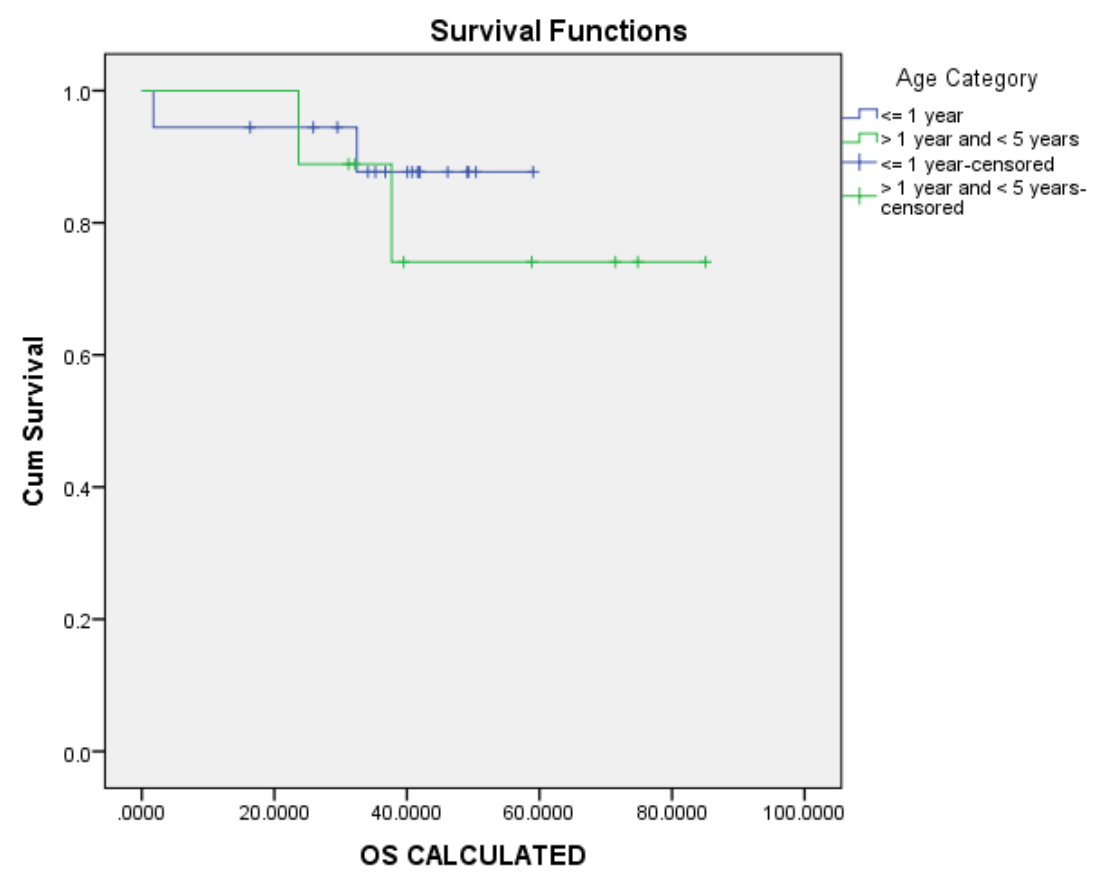

Figure 4. 5 years OS\% in correlation with age category.

Less than or equal 1 year: $87.7 \%$

From 1 to 5 years: $74.1 \%$

$P$ value: 0.505

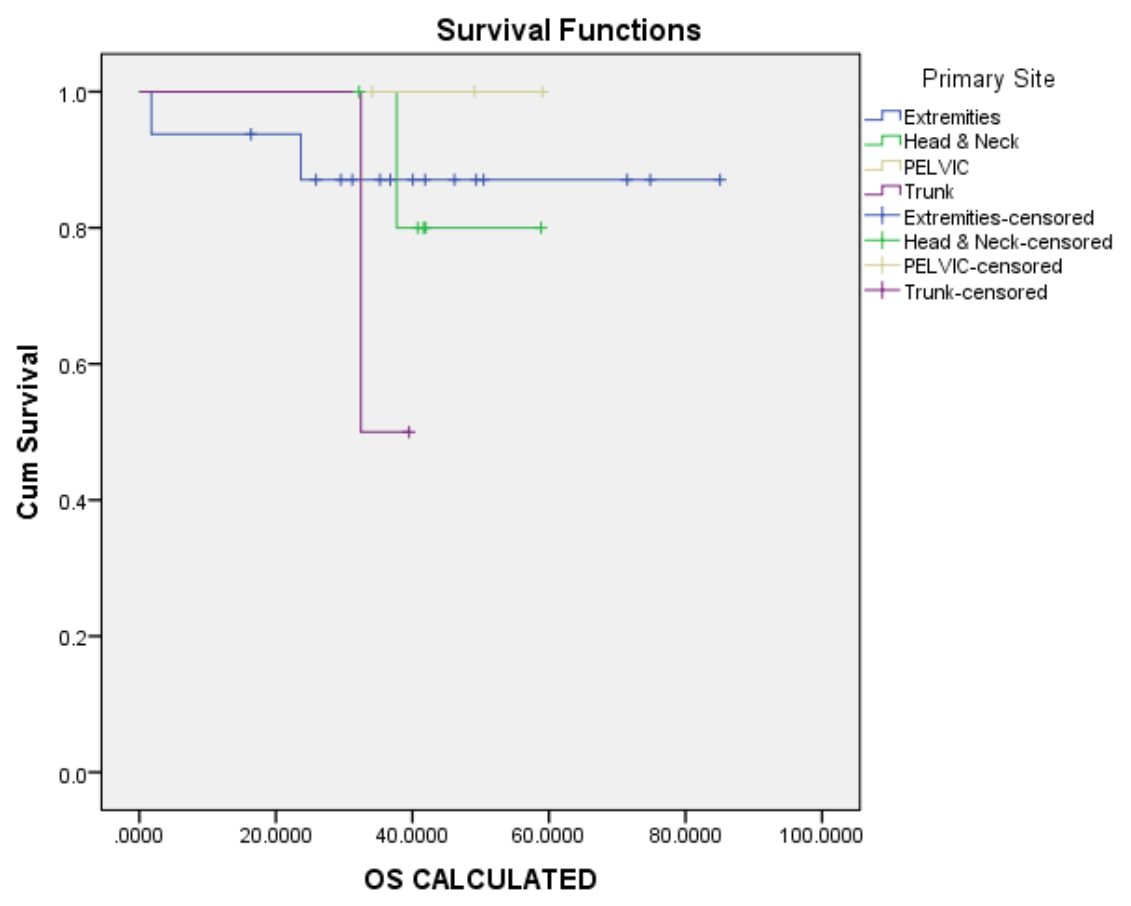

Figure 5. OS IN RELATION TO TUMOR SITE.

3 years OS by site:

Extremities $87.1 \%$

Head and neck $80 \%$

PELVIC $100 \%$

TRUNK $50 \%$

P VALUE: 0.574 


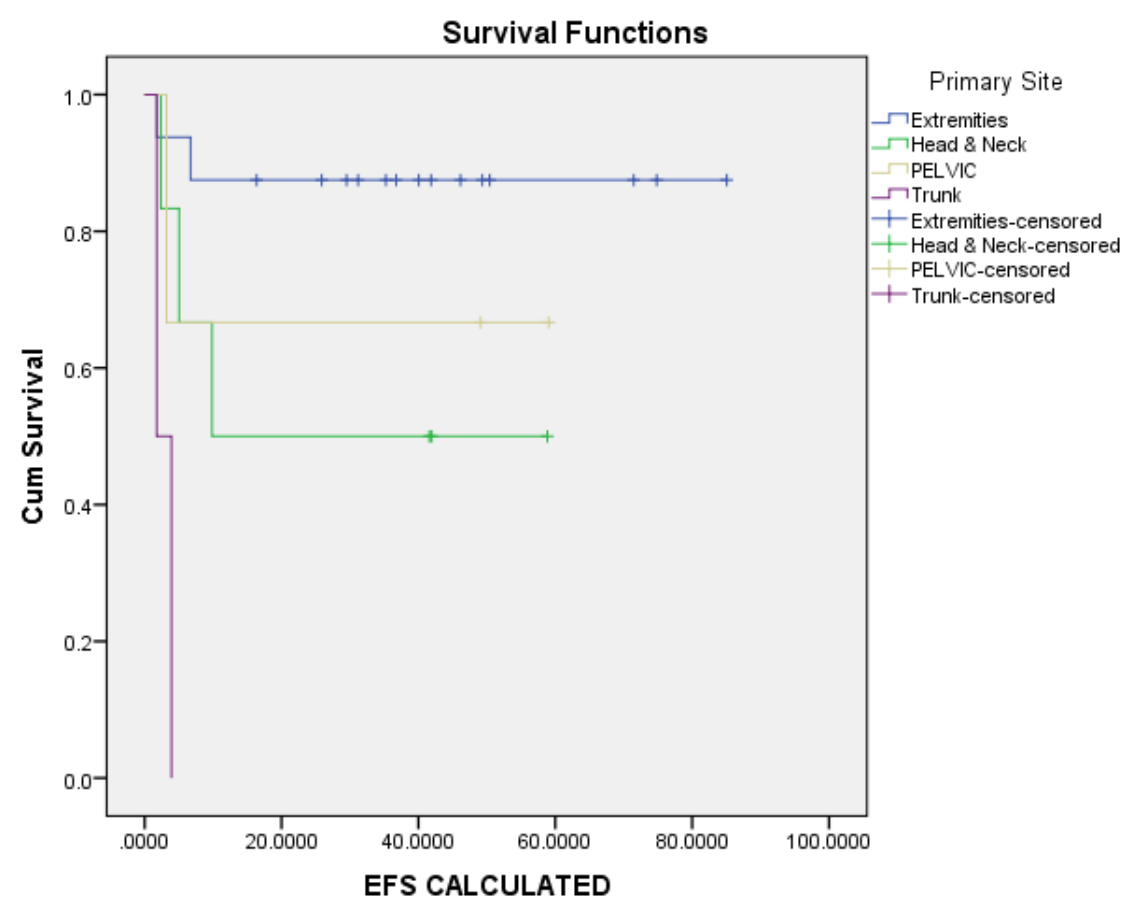

Figure 6. 3 YEARS EFS according to site of the lesion.

Extremities: $87.5 \%$

Pelvic: $66.7 \%$

Head and neck: $50 \%$

Trunk (only 2 patients did not complete even 3 months)

P value: 0.002

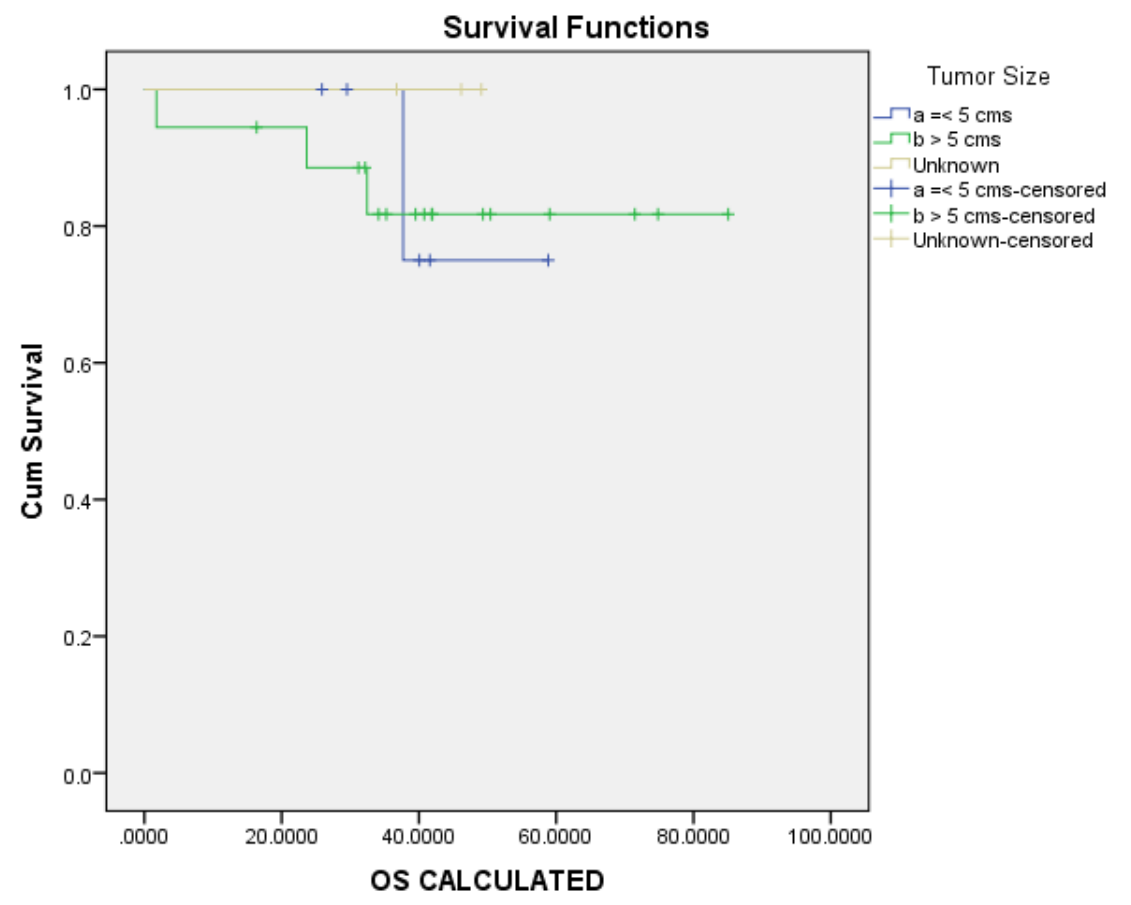

Figure 7. 3 years OS in relation to initial size of the lesion.

Less than $5 \mathrm{~cm}: 75 \%$

More than $5 \mathrm{~cm}: 81.7 \%$

Unknown: $100 \%$

$P$ value: 0.747 


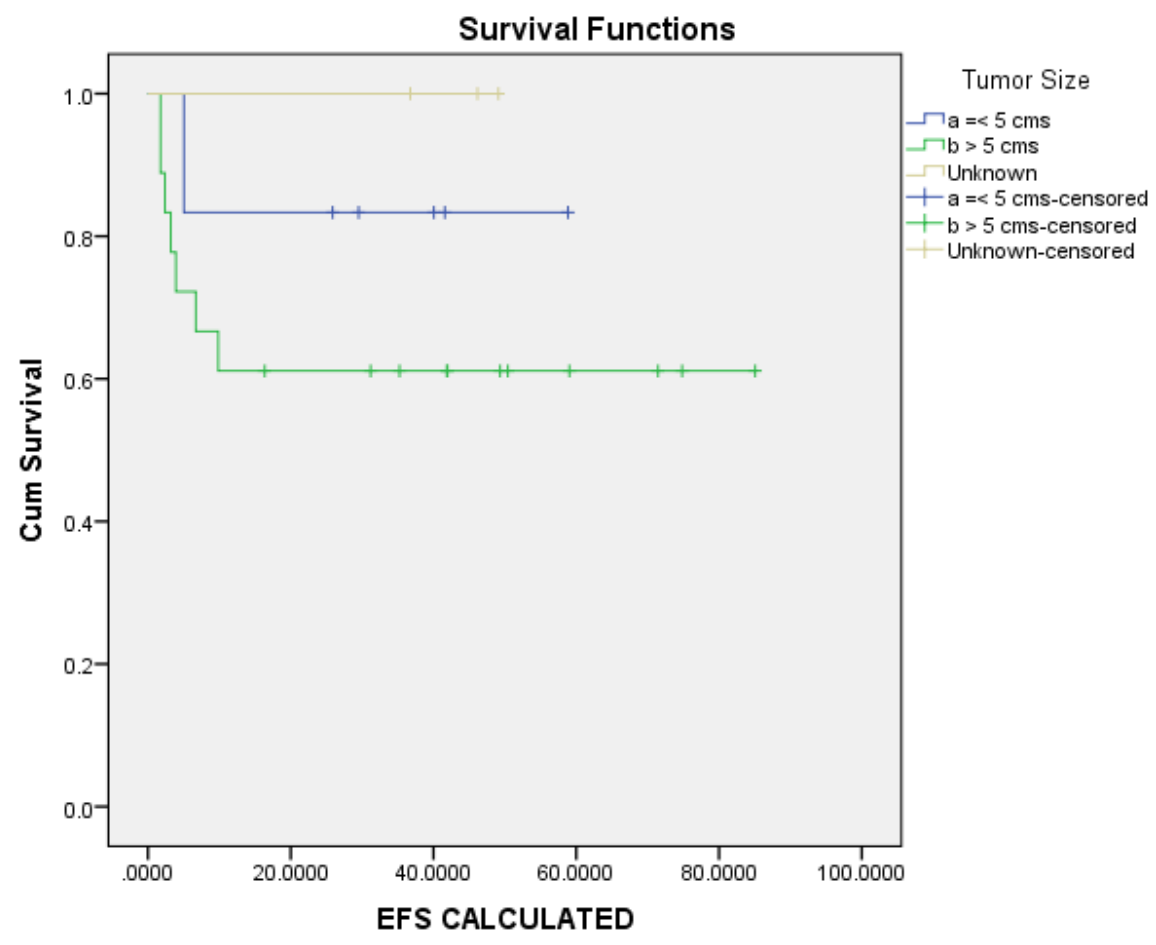

Figure 8. EFS was correlated according to tumor size3 Years.

LESS THAN 5 CM: $83.3 \%$ MORE THAN 5 CM: $61.1 \%$ UN KNOWN SIZE: $100 \%$ P VALUE: 0.316

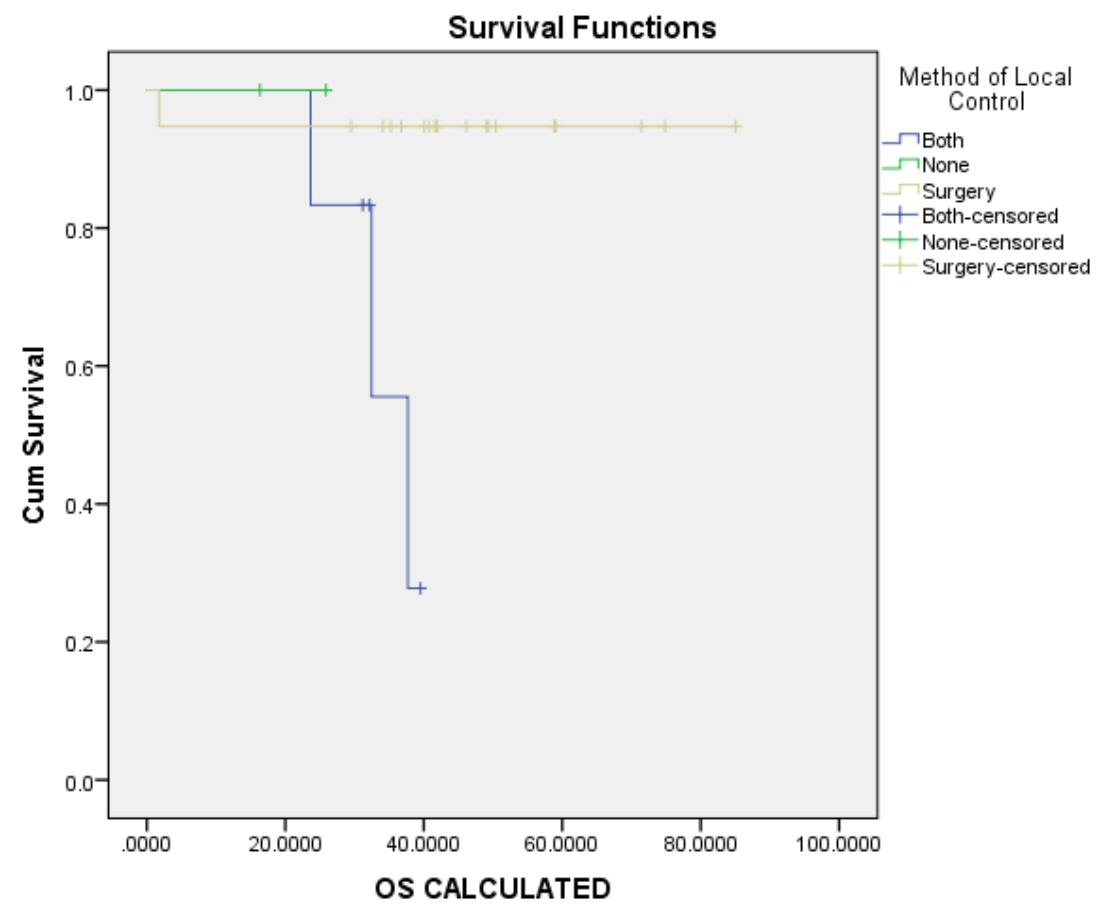

Figure 9. 3 YEARS OS BY METHOD OF LOCAL CONTROL.

BOTH: $27.8 \%$

SURGERY: $94.7 \%$

P: 0.013 


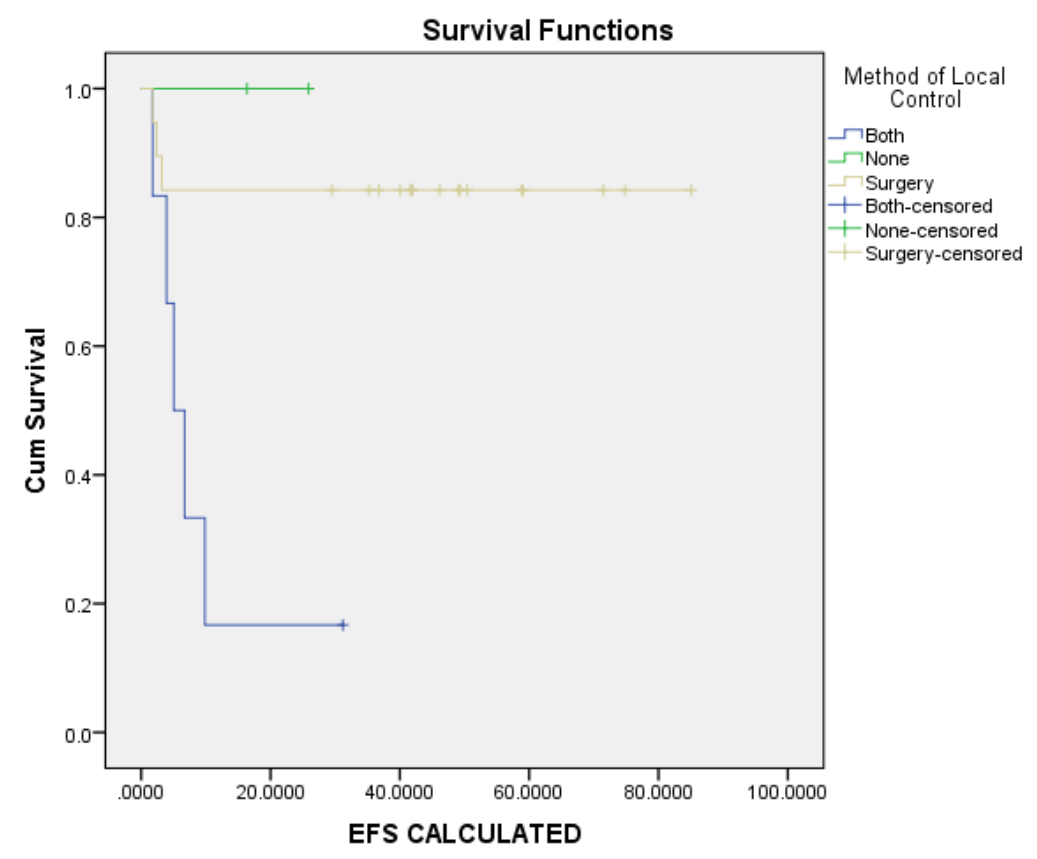

Figure 10. Only 1 year efs (due to the very small number of the none and both categories).

P VALUE: 0.005

SURGERY: $84.2 \%$

BOTH $16.7 \%$

NONE:' $100 \%$

\section{Discussion}

Infantile fibrosarcoma (IFS) is a rare tumor, it is the commonest soft tissue sarcoma in children less than 1 year of age. The histologic diagnosis of fibrosarcoma may sometimes be difficult. In this series, the majority of samples were analyzed by an expert pathologist to confirm the diagnosis proposed by the local pathologist. The age of onset, clinical presentation, and site are suggestive of the diagnosis of IFS, but other clinical diagnoses may also be suggested in the context of a rapidly progressive tumor of an extremity in an infant, such as hemangiomas, hemangiopericytomas, primary myxoid mesenchymal tumor of infancy, or certain fibromatoses as found by AC Yan, et al, 2006. IFS is currently classified as a soft tissue tumor of intermediate malignancy characterized by a quite specific $\mathrm{t}(12 ; 15)$ (p13; q25) translocation coding for an ETV6-NTRK3 gene fusion (23). We did not manage to do genetic analysis of our cases. Congenital infantile fibrosarcoma (CIFS) is a rare neoplasm of infancy that occurs most frequently in the extremities [36]. Surgery is the mainstay of treatment aiming for a conservative resection. Patients with IFS typically respond well to surgical resection and chemotherapy and have an overall survival of $\sim 90 \%$ [37]. However, IFS may present with locally advanced disease and surgery maybe mutilating or cause functional damage (23). In this situation, delayed surgery is advocated. Amputation or disarticulation used to be indicated when obtaining negative surgical margins was not possible by a less aggressive approach [19], but it should be avoided, especially if the tumor does not involve the neurovascular bundle. The primary and secondary amputation rates have been reported to be approximately $50 \%$ [24].

In our study, an initial conservative complete resection was possible in 3 of $27(11 \%)$ patients. This is lower rates than literature due to late presentation and most of our cases $66.7 \%$ presented with tumor size above $5 \mathrm{~cm}$. we tried to avoid mutilating surgery this like another study Orbach D, 2010 showed a rate of $21 \%$ [22].

The outcome for patients who needed only surgery as their treatment was favorable in our study. All three patients who had only surgery were alive at the end of the study period in complete remission. Thirteen cases out of 18 cases with positive margin alive in CR. This group of patients had a median age of 2 months (range 10 days to 9 months) at diagnosis. It has been reported that children whose tumors are completely resected have a $100 \%$ probability of 5 -year survival, but those with residual disease after resection who receive adjuvant therapy still fare well (5-year survival, 76\%) [22]. It was previously reported that the presence of positive postsurgical margins is an important prognostic factor [25]. Positive margins were noted in 17 of our patients. Of these, three patients had recurrence, one patient died of local recurrence and two patients with local recurrence but alive at the end of the study. According to our study, a positive postsurgical margin did not always indicate a poor outcome and this is in agreement with Lalit et al, 2013 (26). Whether chemotherapy is an effective treatment for microscopic positive margins after surgical resection is still not well defined [21]. In our study, none of the 17 patients with a 
positive margin received adjuvant chemotherapy. Positive surgical margins after resection following neoadjuvant chemotherapy may not indicate a poor prognosis [27]. A recent study concluded that most patients with positive margins after resection treated without adjuvant chemotherapy and those with unresectable tumors treated with neoadjuvant chemotherapy were long-term survivors [22] and this in agreement with our study regarding neoadjuvant chemotherapy but we did not treat patients with positive margin they were kept under observation.

Neoadjuvant chemotherapy has been advocated in our study to improve resectability but in other centers they used neoadjuvant chemotherapy to reduce the risk of both local recurrence and metastasis $[22,26]$. Overall survival was $82 \%$ of our patients this lower than was found by Orbach, 2010 (22) who stated that The 5- and 10-year overall survival (OS) rates of his 56 cases were both $89 \%$ (range, $76 \%$ to $95 \%$ ). Local recurrence was observed in 7 of 20 patients in the current study who had resection followed by chemotherapy with or without radiotherapy, the role of adjuvant chemotherapy after initial surgery is less well defined [15, 21, 22, and 25]. Radiation was administered to only one patient with a macroscopic residual in the current study and to 5 cases after recurrence. Cecchetto et al. [3] administered radiotherapy to patients who were 3 years or older and had microscopic or macroscopic residual tumor. Radiotherapy is usually not advocated because it has the potential to impair growth [29].

The probability of local recurrence can be as high as $43 \%$; this usually occurs within 1 year of previous surgery, but may occur 5-31 years after the initial resection [7, 9, 30-32] $\mathrm{m}$ this in disagreement with our study, local recurrence was observed in 7 of $27(25.9 \%)$.

\section{Conclusion}

It confirmed that the overall prognosis of children with IFS was generally satisfactory, with an estimated 5 year survival rate of $82 \%$. These good results were generally achieved with a conservative approach neoadjuvant chemotherapy is indicated in cases in which upfront resection is not feasible. This study shows that most patients with positive margins after surgery treated without adjuvant chemotherapy and patients with unresectable tumor treated with neoadjuvant chemotherapy are long-term survivors. Radiotherapy is indicated for axial primary sites where complete resection is not possible. Due to the deleterious effects on infants, we suggest at present to closely watch them after resection and institute brachytherapy if needed.

\section{References}

[1] Gurney JG, Young JL, Roffers SD, Smith MA, Bunin GR. Soft tissue sarcomas. In: Gloecker Ries IA, Smith MA, Gurney JG, Linet M, Tamra T, Young JL, Bunin GR, editors. SEER pediatric monograph: cancer incidence and survival among children and adolescents, United States SEER program 1975-1995. National Cancer Institute; Bethesda: 1999. pp. 111-124.
[2] Sultan I, Casanova M, Al-Jumaily U, Meazza C, RodriguezGalindo C, Ferrari A. Soft tissue sarcomas in the first year of life. Eur J Cancer. 2010; 46: 2449-2456. [PubMed].

[3] Cecchetto G, Carli M, Alaggio R, Dall'Igna P, Bisogno G, Scarzello G, Zanetti I, Durante G, Inserra A, Siracusa F, Guglielmi M Italian Cooperative Group. Fibrosarcoma in pediatric patients: results of the Italian cooperative group studies (1979-1995) J Surg Oncol. 2001; 78: 225-231. [PubMed].

[4] Ferguson WS. Advances in the adjuvant treatment of infantile fibrosarcoma. Expert Rev Anticancer Ther. 2003; 3: 185-191. [PubMed].

[5] Frieden IJ, Rogers M, Garzon MC. Conditions masquerading as infantile haemangioma: part 2. Australas J Dermatol. 2009; 50: 153-168. [PubMed].

[6] Adibe OO, Juang D, Valusek PA, Holcomb GW, 3rd Snyder CL. Infantile fibrosarcoma: two case reports and literature review. Eur J Pediatr Surg. 2011; 21: 200-202. [PubMed].

[7] Exelby PR, Knapper WH, Huvos AG, Beattie EJ. Soft-tissue fibrosarcoma in children. J Pediatr Surg. 1973; 8: 415-420. [PubMed].

[8] Sivasankar Jayakumar, Sanjana Venkateswaran, Sathish Manivel, Balamurali G Paraspinal Congenital Infantile Fibrosarcoma: A Case Report ournal of Neonatal Surgery 2019; 8: 13 .

[9] Veronica Samedi, Jumana Samara, Ipsita Roy Goswami, Essa Hamdan Al Awad, Rare Presenation of Infantile Fibrosarcoma, Conference: 4th International Neonatology Association ConferenceAt: Ghent, Belgium, Volume: INAC, June 2018, DOI: $10.13140 /$ RG.2.2.36714.16323

[10] Coffin CM, Jaszcz W, O'Shea PA, Dehner LP. So-called congenital-infantile fibrosarcoma: does it exist and what is it? Pediatr Pathol. 1994; 14: 133-150. [PubMed].

[11] Soule EH, Pritchard DJ. Fibrosarcoma in infants and children. A review of 110 cases. Cancer 1977; 40: 1711-1721. 2.

[12] Chung EB, Enzinger FM. Infantile fibrosarcoma. Cancer 1976; 38: 729-739.

[13] Kynaston JA, Malcolm AJ, Craft AW, et al. Chemotherapy in the management of infantile fibrosarcoma. Med Pediatr Oncol 1993; 21: 488-493.

[14] Grier HE, Perez-Atayde AR, Weinstein HJ. Chemotherapy for inoperable infantile fibrosarcoma. Cancer 1985; 56: 15071510 .

[15] Ninane J, Grosseye S, Panteon E, et al. Congenital fibrosarcoma. Preoperative chemotherapy and conservative surgery. Cancer 1986; 58: 1400-1406.

[16] Robinson W, Crawford AH. Infantile fibrosarcoma. Report of a case with long-term follow-up. J Bone Joint Surg 1990; $72-$ A: 291-294.

[17] Vinnicombe SJ, Hall CM. Infantile fibrosarcoma: radiological and clinical features. Skel Radiol 1994; 23: 337-341.

[18] Brock P, Renard M, Smet M, et al. Infantile fibrosarcoma. Med Pediatr Oncol 1991; 19: 210.

[19] Blocker S, Koenig J, Ternberg J. Congenital fibrosarcoma. J Pediatr Surg. 1987; 22: 665-670. [PubMed]. 
[20] Tröbs R, Meier T, Bennek J, Heinrich S, Willnow U. Fibrosarcoma in infants and children: a retrospective analysis - overdiagnosis in earlier years. Pediatr Surg Int. 1999; 15: 123-128. [PubMed].

[21] Loh ML, Ahn P, Perez-Atayde AR, Gebhardt MC, Shamberger RC, Grier HE. Treatment of infantile fibrosarcoma with chemotherapy and surgery: results from the Dana-Farber Cancer Institute and Children's Hospital, Boston. J Pediatr Hematol Oncol. 2002; 24: 722-726. [PubMed].

[22] Orbach D, Rey A, Cecchetto G, Oberlin O, Casanova M, Thebaud E, Scopinaro M, Bisogno G, Carli M, Ferrari A. Infantile fibrosarcoma: management based on the European experience. J. Clin Oncol. 2010; 28: 318-323. [PubMed].

[23] Daniel Orbach a, *, Bernadette Brennan b, Angela De Paoli c, Soledad Gallego d, Peter Mudry e, Nadine Francotte f, Max van Noesel g, Anna Kelsey h, Rita Alaggio i, Dominique Ranche're j, Gian Luca De Salvo c, Michela Casanova k, Christophe Bergeron 1, Johannes H. M. Merks m, Meriel Jenney n, Michael C. G. Stevens o, Gianni Bisogno p, Andrea Ferrari Conservative strategy in infantile fibrosarcoma is possible: The European paediatric Soft tissue sarcoma Study Group experience, European Journal of Cancer 57 (2016) 1e9.

[24] Kurkchubasche AG, Halvorson EG, Forman EN, Terek RM, Ferguson WS. The role of preoperative chemotherapy in the treatment of infantile fibrosarcoma. J Pediatr Surg. 2000; 35: 880-883. [PubMed].

[25] Spunt SL, Poquette CA, Hurt YS, Cain AM, Rao BN, Merchant TE, Jenkins JJ, Santana VM, Pratt CB, Pappo AS. Prognostic factors for children and adolescents with surgically resected non-rhabdomyosarcoma soft tissue sarcoma: an analysis of 121 patients treated at St Jude Children's Research Hospital. J Clin Oncol. 1999; 17: 3697-3705. [PubMed].

[26] Lalit Parida, Israel Fernandez-Pineda, John K. Uffman, Andrew M. Davidoff, Matthew J. Krasin, Alberto Pappo, and Bhaskar N. Rao. Clinical management of infantile fibrosarcoma: a retrospective single-institution review. Pediatr Surg Int. 2013 Jul; 29 (7): 703-708.

[27] Russell H, Hicks MJ, Bertuch AA, Chintagumpala M. Infantile fibrosarcoma: clinical and histologic responses to cytotoxic chemotherapy. Pediatr Blood Cancer. 2009; 53: 2327. [PubMed].

[28] Yan AC, Chamlin SL, Liang MG, Hoffman B, Attiyeh EF,
Chang B, Honig PJ. Congenital infantile fibrosarcoma: a masquerader of ulcerated hemangioma. Pediatr Dermatol. 2006; 23: 330-334. [PubMed].

[29] Pousti TJ, Upton J, Loh M, Grier H. Congenital fibrosarcoma of the upper extremity. Plast Reconstr Surg. 1998; 102: 11581162. [PubMed].

[30] Cofer BR, Vescio PJ, Wiener ES. Infantile fibrosarcoma: complete excision is the appropriate treatment. Ann Surg Oncol. 1996; 3: 159-161. [PubMed].

[31] Hays DM, Mirabal VQ, Karlan MS, Patel HR, Landing BH. Fibrosarcomas in infants and children. J Pediatr Surg. 1970; 5: 176-183. [PubMed].

[32] DeComas AM, Heinrich SD, Craver R. Infantile fibrosarcoma successfully treated with chemotherapy, with occurrence of calcifying aponeurotic fibroma and pleomorphic/spindled celled lipoma at the site 12 years later. J Pediatr Hematol Oncol. 2009; 31: 448-452. [PubMed].

[33] Congenital Infantile Fibrosarcoma Causing Intestinal Perforation in a Newborn, Margarita Kaiser, Bernadette LieglAtzwanger, EszterNagy, DanielaSperl, Georg Singer, and Holger Till, Hindawi Case Reports in Pediatrics Volume 2017, Article ID 2969473, 3 pages https://doi.org/10.1155/2017/2969473.

[34] Assessing the prevalence of a novel oncogene, EML4-NTRK3 https://www.briarcliffschools.org/.../Portfolios_2015_Seniors/j ordana_cohen_paper.pdf (Hashemi, et al., 2013).

[35] AC Yan, SL Chamlin, MG Liang, etal: Congenital infantile fibrosarcoma: A masquerader of ulcerated hemangioma Pediatr Dermatol 23: 330- 334, 2006 Crossref, Medline, Google Scholar.

[36] Enos T, Hosler GA, Uddin N, Mir A' Congenital infantile fibrosarcoma mimicking a cutaneous vascular lesion: a case report and review of the literature J Cutan Pathol. 2017 Feb; 44 (2): 193-200. doi: 10.1111/cup.12854. Epub 2016 Dec 2.

[37] Jonathan Bender, Bailey Anderson, David A. Bloom, Raja Rabah, Rhonda McDougall, Pankaj Vats and Rajen Mody. Refractory and metastatic infantile fibrosarcoma harboring LMNA-NTRK1 fusion shows complete and durable response to crizotinib. Journal of precision medicine, April, 2020, (6) 2: doi: 10.1101/mcs.a003376Cold Spring Harb Mol Case Stud 5: a003376 